\title{
Pautas de terciarización do sector agrario galego: unha aproximación empírica
}

Resumo: Neste traballo analízase a importancia do proceso de terciarización do sector agrario galego e as súas características en relación co modelo agrario rexional. É un fenómeno que recibiu pouca atención na literatura e, porén, é unha realidade dunha importancia crecente para entender o desenvolvemento agrario e o desenvolvemento rexional. A distribución das actividades de servizos dentro do territorio rexional e 0 contido desas actividades é moi relevante para frear o abandono do espazo rural e garantir a cohesión dentro do territorio.

O estudo baséase na análise dos datos estatísticos dispoñibles. En concreto, a visión agregada apórtana os datos do Marco Input Output de Galicia e as Contas Económicas da Agricultura. Namentres, os datos do Censo Agrario e a Enquisa de Estrutura das Explotacións Agrarias permiten unha análise dende o punto de vista microeconómico. Obsérvase unha crecente utilización de servizos por parte do sector agrario galego alomenos durante a década de 1990 e unha ralentización nos anos máis recentes. A análise do contido dos servizos permite identificar unha notable importancia da externalización de actividades e funcións propias do proceso produtivo agrario, así como o dinamismo de certos servizos intensivos en coñecemento, chave en certas actividades agrarias e no seu proceso de innovación.

Palabras Chave: terciarización, cambio estrutural, sector agrario, innovación, desenvolvemento rexional

\section{Tertiarization patterns in the Galician agricultural sector: an empirical approach}

Abstract: In this paper the importance of the tertiarisation of the Galician agricultural sector and its main features in relation to the regional agricultural sector are analysed. It is a phenomenon that has received scarce attention in the literature, though it is a reality that deserves attention in order to favour the understanding of the agricultural and regional development. The distribution of service activities in the regional territory and the content of these activities are very relevant to hinder the abandonment of the rural space and to guarantee the internal cohesion of the territory.

The study is based on the analysis of the available statistical data. In particular, the aggregated view comes from the Input-Output data and the Economic Accounts of Agriculture. A microanalysis of the phenomenon is carried out according to the Censo Agrario and the Encuesta de Estructura de las Explotaciones Agrarias. There is an increasing utilisation of services on behalf of the Galician agricultural sector along the 1990's decade, later decreasing in more recent years. The analysis of the content of services allows to identify the importance of outsourcing of specific tasks and functions of the agricultural productive process, as well as the dynamism of certain knowledge-intensive business services, which are key for innovation processes in the agricultural sector.

Keywords: tertiarisation, estructural change, agricultural sector, innovation, regional development

\section{Introdución}

\footnotetext{
* Ángeles Pereira Sánchez, angeles.pereira@usc.es e Xavier Vence Deza, xavier.vence@usc.es. Facultade de Ciencias Económicas e Empresariais, Avda. do Burgo das Nacións, s/ n, 15782 Santiago de Compostela (Spain) Nota: Unha versión previa deste traballo foi aceptada como ponencia na XLII Reunión de Estudios Regionales, en Santiago de Compostela do 16 ao 18/ 11/ 2016.
} 
O cambio estrutural do sector agrario conta cunha longa traxectoria de investigación nos estudos de economía rexional (Compés López, López Iglesias e Martínez Gómez, 2011; Fernández Leiceaga e López Iglesias, 2000; López-Iglesias, Sineiro-García, e LorenzanaFernández, 2013). Perante o enfoque máis tradicional que se centraba nas dinámicas internas do sector, principalmente no tamaño das unidades produtivas, a tecnoloxía e características de produción, a caracterización da forza de traballo, a propiedade dos recursos e modelos de financiamento, así como nas relacións intra- e inter-sectoriais, dende a perspectiva evolucionista, a estrutura agraria e o cambio estrutural agrario deben definirse de forma máis ampla. Estes "deben incluír a imbricación das explotacións agrarias e a súa interacción coas cadeas de valor agroalimentarias, a sociedade (rural), a economía e o contexto (rurais), así como coas institucións e políticas" (Balmann, Dautzenberg, Happe e Kellermann, 2006, p. 115).

Dende esa perspectiva, toma unha fundamental relevancia o estudo dos servizos e a súa relación coas actividades agrarias, polo papel que se lles atribúe aos primeiros na innovación de sectores máis tradicionais e como ferramenta de diversificación das fontes de emprego no ámbito rural, contribuíndo así á competitividade e cohesión dentro do territorio rexional.

Segundo as estimacións do Instituto Galego de Estatística (IGE), en 2013 a rama agraria galega era responsable do 3,3 por cento do valor engadido bruto xerado na Comunidade Autónoma, e de case un 5 por cento dos postos de traballo equivalentes a tempo completo. Ao longo das últimas tres décadas é notable a transformación experimentada polo sector, cun aumento da produción en termos reais do 40 por cento dende 1990 (Afundación, 2016) e unha caída da poboación ocupada, representando na actualidade pouco máis do 11\% da poboación ocupada no sector no ano 1985 (Pereira Sánchez, 2016).

Este artigo estuda a terciarización da agricultura como unha innovación de sistema, que vén dada pola conxunción de diversos factores, endóxenos ao sector agrario e externos ao mesmo. O cambio estrutural agrario ocorre no contexto máis amplo do cambio rural, caracterizado pola perda de importancia das actividades económicas tradicionais, o éxodo masivo, a perda de cultura e valores propios do rural xunto coa chegada de novos valores urbanos. Estes cambios determinan conxuntamente a terciarización do espazo rural, tanto pola localización de actividades de servizo como polas novas necesidades da poboación asentada no rural (Melero e Calatrava, 2007). Porén, a terciarización do sector agrario ten unhas características propias e responde a factores específicos. A hipótese que se formula é que a terciarización do sector agrario constitúe unha resposta adaptativa do sector aos complexos cambios de mercado, sociais e institucionais.

A orixinalidade do presente estudo radica no enfoque de sistema adoptado no estudo da relación entre os servizos e a agricultura. Os estudos de economía agraria no ámbito español centráronse en aspectos parciais da terciarización, fundamentalmente na externalización de traballos por parte das explotacións agrarias e na relación do fenómeno coa agricultura a tempo parcial (Arnalte, 1989, 2002; Gallego Bono, 2010; Moragues-Faus, 2014). O mesmo enfoque aplicouse en estudos relativos a outras agriculturas (Aparicio, Berenguer e Rau, 2004; Errington, 1998; Harff e Lamarche, 1998; Pugliese e CerianiSebregondi, 1981). Por outra banda, estudos máis recentes centráronse nas consecuencias da privatización dos servizos de extensión agraria (Labarthe, 2009; Prager, Labarthe, Caggiano e Lorenzo-Arribas, 2016).

O estudo da terciarización como unha dimensión relevante do cambio estrutural que caracteriza ás economías desenvolvidas deu lugar a unha crecente investigación nos últimos anos. En concreto, a imbricación entre as actividades de servizo e industriais é un dos aspectos que máis interese suscitou (Boden e Miles, 2000; Cuadrado Roura e Del Río 
Gómez, 1987, 1993; Miles, 1993). Por outra banda, está amplamente aceptada a hipótese da industrialización da agricultura (Goodman, Sorj e Wilkinson, 1987). En cambio, a pesar da importancia da relación dos servizos coa agricultura, hai un vacío teórico e analítico sobre a terciarización do sector agrario e sobre como esta afecta á localización de actividades e á xeración de emprego no territorio rexional.

Este artigo procura cubrir ese oco coa análise das pautas de terciarización do sector agrario galego ao longo das últimas tres décadas. Para levar a cabo a análise, utilízase a información estatística dispoñible. $\mathrm{O}$ artigo está estruturado en catro partes: logo desta introdución, na segunda sección revísase a literatura sobre a terciarización e o cambio estrutural, con énfase na terciarización da agricultura e o cambio estrutural agrario galego. A continuación, preséntanse as fontes de datos empregadas neste artigo. Na sección cuarta descríbense os principais resultados; na quinta, discútense en relación á literatura e, finalmente, expóñense as conclusións.

\section{A terciarización e o cambio estrutural no sector agrario}

A terciarización das economías ou o importante peso das actividades de servizo, en termos de produción e de emprego, é un dos feitos máis singulares do cambio estrutural que afecta aos países desenvolvidos. Nos estudos de carácter económico, a terciarización explicouse por diversos factores, sendo dominantes as visións nos últimos anos dun cambio na composición da estrutura produtiva dos países debido á crise da agricultura eá desindustrialización, así como á crecente imbricación entre actividades industriais y de servizos, que se manifesta especialmente no crecementos dos chamados servizos a empresas (Cuadrado Roura e Del Río Gómez, 1987, 1993; Rubalcaba Bermejo e Kox, 2009).

A relación entre as actividades agrarias e de servizos recibiu unha menor atención, se ben como indica Bourgeois (1987) o terciario agrícola formouse de certo antes que os demais, en forma de organizacións profesionais agrarias (sindicatos), cooperativas e mutuas, así como técnicos da administración encargados de ofrecer consello técnico ao sector. En estudos referidos ao ámbito español, o estudo da terciarización do sector agrario centrouse case exclusivamente no fenómeno da externalización de tarefas e na identificación destas actividades de servizos ao sector. Arnalte (1989; 2002) califica a externalización das actividades agrarias como unha nova forma de organización da produción agraria, alternativa ao axuste estrutural clásico que conduciría ao peche e desaparición das explotacións máis pequenas.

A contratación externa de servizos, principalmente de maquinaria pero nalgúns casos tamén de tarefas manuais, e incluso da xestión global da explotación, relacionouse con distintos factores:

- Factores económicos

Nun contexto de forte competitividade, as explotacións procuran reducir os seus custos de produción, substituíndo custos fixos por outros de carácter máis variable (servizos de maquinaria, contratación eventual) (Harff e Lamarche, 1998).

A crecente especialización da produción agrícola e a intensificación leva a un maior número de tarefas reiterativas e tamén a picos de actividade que facilitan a contratación externa (Errington, 1998). No senso contrario, unha estrutura diversificada da produción tamén necesita contratistas agrarios que aporten flexibilidade (Igata, Hendriksen e Heijman, 1997).

- $\quad$ Factores tecnolóxicos 
A incorporación de innovacións que requiren economías de escala en moitos casos só é posible para as pequenas explotacións mediante a contratación de servizos externos (Arnalte, 1989; Langreo, 2002).

Adicionalmente, a continua innovación e evolución tecnolóxica do sector baséase en novas competencias (coñecementos e habilidades), polo que a especialización funcional e a expertise adicional a miúdo depende de axentes externos (Errington, 1998; Harff e Lamarche, 1998).

- $\quad$ Factores laborais

A notable caída da axuda familiar nas explotacións, a extensión da agricultura a tempo parcial, que teñen que ver coa oportunidade de traballo fóra da explotación, levan a unha maior demanda de servizos externos (Errington, 1998; Gallego Bono, 2010; Harff e Lamarche, 1998; Langreo, 2002; Moragues-Faus, 2014).

\section{- $\quad$ Factores sociais}

Os traballadores ocupados no sector agrario desexan estilos de vida contemporáneos, con horarios regulares e períodos de descanso. Por iso, contrátanse a axentes externos para a realización de traballos non esenciais da explotación, para a substitución en períodos determinados ou emerxencias, etc. Noutros casos, a idade avanzada de moitos titulares de explotacións impídelles ocuparse das tarefas agrarias. Por último, o atractivo da granxaresidencia leva a persoas sen experiencia agraria ou con limitacións de tempo para asumir certas tarefas, a contratar empresas de servizos (Errington, 1998; Harff e Lamarche, 1998).

\subsection{Cambio estrutural e crise no sector agrario galego}

Ao longo da década de 1960 o sector agrario galego viviu un relativamente tardío pero acelerado proceso de transformación, que tivo como trazos máis destacados a orientación cara o mercado da produción agraria e, xunto con ela, o inicio da capitalización das explotacións, mediante a adquisición externa de inputs e de maquinaria. Neste contexto comeza a definirse a especialización gandeira fronte ao policultivo intensivo de subsistencia que caracterizara anteriormente a agricultura tradicional galega (Díaz Díaz, 1979).

Cando o sector agrario galego estaba aínda iniciando o seu proceso de cambio estrutural , viuse afectado por un contexto de crecente liberalización comercial debido á integración do Estado Español na Comunidade Económica Europea (CEE) en 1986 e, como consecuencia, á aplicación da Política Agraria Común e dos acordos da Rolda Uruguai do GATT (Fernández Leiceaga e López Iglesias, 2000). O sector agrario galego sofre un intenso declive durante as últimas décadas do século $\mathrm{XX}$, que é consecuencia deste contexto e que é afectado pola intensa mecanización das explotacións e a crecente integración coa industria. Así, prodúcese unha forte caída da poboación ocupada nas actividades agrarias e unha notable redución do número de explotacións agrarias (Fernández Leiceaga e López Iglesias, 2000; López-Iglesias, 1996).

Nas décadas máis recentes, segundo os datos do Censo Agrario (1999 e 2009) e da Enquisa de Estruturas da Explotacións Agrícolas (2013) a transformación do sector agrario galego pódese resumir nos seguintes trazos: 1) importante redución no número de explotacións, especialmente entre as de menor dimensión (menos de 10 hectáreas), namentres que se mantén a Superficie Agrícola Utilizada (SAU), o que determina un aumento da superficie media xestionada por cada explotación (de 5,55 hectáreas en 1999 a 8,36 en 2013); 2) crecente concentración da SAU, son as explotacións máis grandes (un $23 \%$ do total) as que xestionan practicamente o $75 \%$ da terra produtiva; 3) o sector é 
intensivo abondo, a ratio que mide a Produción Estándar Total polo número de hectáreas de SAU multiplica en 2,26 veces a correspondente á agricultura española; 4) intensa caída da poboación ocupada no sector; segundo os datos da Enquisa de Poboación Activa (EPA) en 2015 hai 45.600 persoas ocupadas no sector, o que supón tan só o $11 \%$ da poboación ocupada no mesmo en 1985; 5) consolidación da especialización produtiva gandeira, sendo o bovino de leite e a gandaría sen terras as principais producións do sector (42 por cento e 27 por cento, respectivamente).

Conforme a unha definición ampla do cambio estrutural, debemos entender a caracterización actual do sector agrario galego como o resultado da co-evolución dinámica dos cambios tecnolóxicos, institucionais e de mercado. Neste senso, a hipótese que formulamos é que a terciarización do sector agrario responde á resposta adaptativa do sector á crecente complexidade tecnolóxica, institucional e de mercado.

\section{Metodoloxía}

Para a realización deste estudo baseámonos na análise da información estatística dispoñible en varias fontes relativas ao sector agrario galego. En primeiro lugar, analizamos os datos contidos nas táboas de destino a prezos de adquisición do Marco Input Output de Galicia (Miogal) dos anos 1998, 2005, 2008 e 2011, elaboradas conforme á metodoloxía SEC-95. A sub-matriz que representa os consumos intermedios de servizos (filas) por parte das ramas agraria e gandeira (columnas), permite coñecer os servizos que son demandados como consumos intermedios e as necesidades directas de inputs de servizos na produción agraria.

En segundo lugar, revisamos as Contas Económicas da Agricultura, que teñen por obxectivo medir, describir e analizar a formación de renda procedente da actividade económica agraria orientada ao mercado. A contabilización dos consumos intermedios nestas contas reflicte a conexión da agricultura con outras ramas da economía a través dos inputs. Os consumos intermedios representan o valor de todos os bens e servizos consumidos no proceso produtivo agrario e inclúen: sementes e plantas de viveiro, enerxía, fertilizantes, fitosanitarios, alimentos para o gando, gastos veterinarios, mantemento e reparacións de edificios e maquinaria, servizos agrícolas e outros servizos. $\mathrm{Na}$ Táboa A.1. (Anexo) presentamos unha síntese dos diferentes servizos que se contabilizan como consumos intermedios.

En terceiro lugar, os datos do Censo Agrario de 2009 e da Enquisa de Estruturas das Explotacións Agrarias de 2013 permiten analizar con datos de carácter microeconómico a evolución da cuestión relativa ao "traballo realizado por persoas non empregadas directamente polo titular". Esta defínese como o "número de xornadas traballadas na explotación por persoas que non foron empregadas directamente polo titular durante os doce meses da campaña agrícola, por exemplo autónomos ou asalariados de empresas contratadas. Exclúense os traballos efectuados por empresas de contabilidade e os traballos de axuda mutua nos que non medie remuneración" (INE, 2013, p. 48). Polo tanto, esta fonte permite coñecer un aspecto chave da terciarización da agricultura como é a externalización de tarefas.

\section{Tendencias na terciarización do sector agrario galego}

A terciarización do sector agrario, entendida como a intensificación no uso de inputs de servizo pola rama de agricultura, é un fenómeno observable a través do Miogal (Táboa 1). Os datos desta fonte estatística presentan notables oscilacións relativas ao cómputo dos servizos, polo que deben ser tomados con cautela.

O MIOGAL 2011 presenta o dato de produtos e servizos agrícolas de maneira agregada. Nesta táboa incluímos unha estimación, que é a cifra correspondente a servizos agrícolas 
recollida nas Contas Rexionais da Agricultura do Magrama e que ascende a 7,7 millóns de euros para ese ano.

A análise detallada das diferentes partidas de servizos (Táboa 2) permite identificar algunhas cuestións relevantes:

- Os servizos máis directamente relacionados co proceso produtivo das explotacións agrarias son os máis importantes con relación aos consumos intermedios e polo tanto, definitorios da terciarización da agricultura. En concreto, os servizos veterinarios de mercado constitúen unha das partidas máis importantes dos consumos intermedios. Igualmente, destacan os servizos agrícolas e gandeiros, que supoñen a externalización de tarefas de apoio.

- Determinadas actividades que se poden definir como servizos intensivos en coñecemento son importantes consumos intermedios e determinantes na terciarización da agricultura: servizos administrativos, de oficina e outros servizos de axuda ás empresas; servizos de consultoría, ensaio e análise técnica.

- Os servizos de intermediación financeira; de seguros e plans de pensións tamén teñen importancia para o sector agrario galego.

Táboa 1. Evolución de magnitudes da rama Agricultura, gandaría, caza e servizos das actividades relacionadas con elas. Galicia

\begin{tabular}{lllll}
\hline & 1998 & 2005 & 2008 & 2011 \\
\hline Produción Agraria* (miles de euros) (PA) & 1.750 .676 & 2.276 .019 & 2.669 .744 & 3.152 .456 \\
\hline $\begin{array}{l}\text { Consumos Intermedios (miles de euros) } \\
\text { (CI) }\end{array}$ & 756.064 & 972.598 & 1.099 .125 & 1.636 .274 \\
\hline Servizos (miles de euros) & 116.739 & 76.144 & 121.867 & 78.962 \\
\hline CI / PA (\%) & 43,19 & 42,73 & 41,17 & 51,90 \\
\hline Servizos / CI (\%) & 15,44 & 7,83 & 11,09 & 4,83 \\
\hline Servizos / PA (\%) & 6,67 & 3,35 & 4,56 & 2,50 \\
\hline$*$ precios bá & & & & \\
\hline
\end{tabular}

*precios básicos. Fonte: Elaboración propia IGE: MIOGAL. Anos 1998, 2005, 2008, 2011

A notable variabilidade dos datos impide realizar unha análise máis fonda do Miogal que permita reflectir fidedignamente á terciarización do sector agrario.

A Táboa 3 presenta a evolución a prezos correntes das magnitudes agrarias da produción, os consumos intermedios e cada unha das partidas referidas a servizos das Contas Económicas da Agricultura. Destacan os seguintes aspectos, distinguindo entre sub-etapas pola existencia de rompementos nas series de datos:

Na década de 1990 obsérvase un incremento do gasto global en "Servizos" do 45,5\% pero convén distinguir por partidas: o maior gasto corresponde a "Mantemento de materiais", "Mantemento de edificios" e "Gastos veterinarios". Entre eles, destaca sobre todo o incremento que se produce ao longo do período en "Gastos veterinarios", pois practicamente duplícase. Se ben o importe dos "Servizos agrícolas" é de importancia menor no conxunto, é moi destacable o notable incremento deste gasto ao longo da década (practicamente un 125\%). 
Táboa 2. Importancia dos servizos como consumo intermedio e terciarización do sector agrario galego

\begin{tabular}{|c|c|c|c|c|}
\hline & 1998 & 2005 & 2008 & 2011 \\
\hline & $\begin{array}{lll}000 & \% \mathrm{CI} & \% \mathrm{PA}\end{array}$ & $\begin{array}{lll}000 & \% \text { CI } & \% \text { PA }\end{array}$ & $\begin{array}{lll}000 & \% \text { CI } & \% \text { PA }\end{array}$ & $\begin{array}{lll}000 & \% \mathrm{CI} & \% \mathrm{PA}\end{array}$ \\
\hline Servizos agrícolas e gandeiros & $\begin{array}{lll}76 & 0,01 & 0,00\end{array}$ & $12.046 \quad 1,24 \quad 0,53$ & $13.7411,250,51$ & $7.700^{\mathrm{a}} 0,470,24$ \\
\hline Serv. veterinarios de mercado & $14.301 \quad 1,89 \quad 0,82$ & $26.098 \quad 2,68 \quad 1,15$ & $40.892 \quad 3,72 \quad 1,53$ & $29.2221,790,93$ \\
\hline $\begin{array}{l}\text { Serv. de intermediación } \\
\text { financeira }\end{array}$ & $8.0491,06 \quad 0,46$ & $17.9781,850,79$ & $16.489 \quad 1,50 \quad 0,62$ & $12.7050,780,40$ \\
\hline $\begin{array}{l}\text { Serv. de seguros e plans de } \\
\text { pensións }\end{array}$ & $1.9610,260,11$ & $3.5510,370,16$ & $10.9771,000,41$ & $8.1810,500,26$ \\
\hline $\begin{array}{l}\text { Servizos relacionados co } \\
\text { emprego }\end{array}$ & $:$ & : & $\begin{array}{lll}751 & 0,07 & 0,03\end{array}$ & $2.382 \quad 0,15 \quad 0,08$ \\
\hline $\begin{array}{l}\text { Servizos administrativos, de } \\
\text { oficina e outros Servizos de } \\
\text { axuda ás empresas; ... }\end{array}$ & : & & $19.381 \quad 1,76 \quad 0,73$ & $2.248 \quad 0,14 \quad 0,07$ \\
\hline $\begin{array}{l}\text { Serv. xurídicos, de } \\
\text { contabilidade, etc. }\end{array}$ & $376 \quad 0,05 \quad 0,02$ & $2.643 \quad 0,27 \quad 0,12$ & $341 \quad 0,03 \quad 0,01$ & $2.040 \quad 0,12 \quad 0,06$ \\
\hline $\begin{array}{l}\text { Serv. de consultoría, ensaio e } \\
\text { análise técnica }\end{array}$ & $\begin{array}{lll}1.447 & 0,19 & 0,08\end{array}$ & $\begin{array}{lll}7.357 & 0,76 & 0,32\end{array}$ & $\begin{array}{lll}7.695 & 0,70 & 0,29\end{array}$ & $893 \quad 0,05 \quad 0,03$ \\
\hline $\begin{array}{l}\text { Serv. de saneamento público de } \\
\text { mercado / Serv. de atención } \\
\text { sanitaria de mercado }\end{array}$ & $4.254 \quad 0,56 \quad 0,24$ & $\begin{array}{lll}.334 & 0,14 & 0,06\end{array}$ & $\begin{array}{lll}1.099 & 0,10 & 0,04\end{array}$ & $818 \quad 0,05 \quad 0,03$ \\
\hline Serv. de educación de mercado & $237 \quad 0,03 \quad 0,01$ & $:$ & $2.198 \quad 0,20 \quad 0,08$ & $255 \quad 0,02 \quad 0,01$ \\
\hline Serv. de telecomunicacións & $2.969 \quad 0,39 \quad 0,17$ & $:$ & $1.099 \quad 0,10 \quad 0,04$ & $127 \quad 0,01 \quad 0,00$ \\
\hline $\begin{array}{l}\text { Serv. auxiliares á intermediación } \\
\text { financeira }\end{array}$ & $: \quad:$ & $:$ & $\begin{array}{lll}.099 & 0,10 & 0,04\end{array}$ & $\begin{array}{lll}72 & 0,00 & 0,00\end{array}$ \\
\hline $\begin{array}{l}\text { Outros serv. empresariais } \\
\text { n.c.o.p./ Outros servizos } \\
\text { profesionais, científicos e } \\
\text { técnicos }\end{array}$ & $\begin{array}{lll}5.005 & 0,66 & 0,29\end{array}$ & $:$ & $550 \quad 0,05 \quad 0,02$ & $\begin{array}{lll}64 & 0,00 & 0,00\end{array}$ \\
\hline Serv. de I+D de mercado & $\begin{array}{lll}451 & 0,06 & 0,03 \\
\end{array}$ & $604 \quad 0,06 \quad 0,03$ & $6600,06 \quad 0,02$ & $:$ \\
\hline Serv. de asociacións n.c.o.p. & $181 \quad 0,02 \quad 0,01$ & $: \quad:$ & $680 \quad 0,06 \quad 0,03$ & $\begin{array}{lll}766 & 0,05 & 0,02 \\
\end{array}$ \\
\hline $\begin{array}{l}\text { Serv. doutros transportes } \\
\text { terrestres }\end{array}$ & $\begin{array}{lll}46.810 & 6,19 & 2,67\end{array}$ & $\begin{array}{lll}0 & 0,00 & 0,00\end{array}$ & $\begin{array}{lll}0 & 0 & 0\end{array}$ & $\begin{array}{lll}4.500 & 0,28 & 0,14\end{array}$ \\
\hline Serv. anexos ao transporte & $24.549 \quad 3,25 \quad 1,40$ & $\begin{array}{lll}117 & 0,01 & 0,01 \\
\end{array}$ & $\begin{array}{lll}660 & 0,06 & 0,02 \\
\end{array}$ & $4.077 \quad 0,250,13$ \\
\hline $\begin{array}{l}\text { Reparación de vehículos de } \\
\text { motor }\end{array}$ & $2.608 \quad 0,34 \quad 0,15$ & $665 \quad 0,07 \quad 0,03$ & $1.3570,120,05$ & $2.157 \quad 0,130,07$ \\
\hline $\begin{array}{l}\text { Serv. de transp. por estrada de } \\
\text { pasaxeiros }\end{array}$ & $\begin{array}{lll}5 & 0,00 & 0,00\end{array}$ & : & : & $500 \quad 0,03 \quad 0,02$ \\
\hline $\begin{array}{l}\text { Serv. de comercio ao por maior } \\
\text { e de intermediarios }\end{array}$ & $\begin{array}{lll}0 & 0,00 & 0,00\end{array}$ & $\begin{array}{lll}3.751 & 0,39 & 0,16\end{array}$ & $\begin{array}{lll}2.198 & 0,20 & 0,08\end{array}$ & $255 \quad 0,02 \quad 0,01$ \\
\hline $\begin{array}{l}\text { Serv. de alugueiro de } \\
\text { maquinaria e equipo }\end{array}$ & $\begin{array}{lll}1.399 & 0,19 & 0,08\end{array}$ & $:$ & $:$ & $:$ \\
\hline $\begin{array}{l}\text { Serv. de transporte por } \\
\text { ferrocarril }\end{array}$ & $\begin{array}{lll}2.061 & 0,27 & 0,12\end{array}$ & $:$ & $:$ & $:$ \\
\hline Total Servizos (A) & $\begin{array}{l}116.739 \\
15,44 \\
6,67 \\
\end{array}$ & $\begin{array}{l}76.144 \\
7,83 \\
3,35 \\
\end{array}$ & $\begin{array}{l}121.867 \\
11,09 \\
4,56\end{array}$ & $\begin{array}{l}78.962 \\
4,83 \\
2,50 \\
\end{array}$ \\
\hline Consumos Intermedios & $\begin{array}{l}756.064 \\
100,00 \\
43,19 \\
\end{array}$ & $\begin{array}{l}972.598 \\
100,00 \\
42,73 \\
\end{array}$ & $\begin{array}{l}1.099 .125 \\
100,00 \\
41,17\end{array}$ & $\begin{array}{l}1.636 .274 \\
100,00 \\
51,90\end{array}$ \\
\hline Produción & $\begin{array}{ll}1.750 .676 & 100 \\
\end{array}$ & 2.276 .019100 & $2.669 .744 \quad 100$ & 3.152 .456100 \\
\hline Servizos / CI & 15,44 & 7,83 & 11,09 & 4,83 \\
\hline Servizos / PA & 6,67 & 3,35 & 4,56 & 2,50 \\
\hline
\end{tabular}

aMIOGAL 2011 presenta o dato de produtos e servizos agrícolas de maneira agregada. A estimación está baseada na cifra de servizos agrícolas recollida nas Contas Rexionais de Agricultura publicadas polo Magrama, que ascende a 7,7 milloóns de euros. \% CI = (A) / CI (\%); \% PA= (A) / PA (\%). Fonte: Elaboración propia a partir de IGE: MIOGAL 1998, 2005, 2008, 2011 
Táboa 3. Evolución das magnitudes da Produción Agraria (PA), Consumos Intermedios (CI) e Servizos, e das ratios Servizos / PA e Servizos / CI. En millóns de euros correntes

\begin{tabular}{|c|c|c|c|c|c|c|c|c|c|c|c|}
\hline & $\begin{array}{l}\text { (A) } \\
\text { Produc } \\
\text { ión } \\
\text { Agraria }\end{array}$ & $\begin{array}{l}\text { (B) } \\
\text { Consum } \\
\text { os } \\
\text { Interme } \\
\text { dios }\end{array}$ & $\begin{array}{l}\text { Gastos } \\
\text { veterina } \\
\text { rios }\end{array}$ & $\begin{array}{l}\text { Manteme } \\
\text { nto } \\
\text { materiai } \\
\text { s }\end{array}$ & $\begin{array}{l}\text { Manteme } \\
\text { nto } \\
\text { edificios }\end{array}$ & $\begin{array}{l}\text { Serviz } \\
\text { os } \\
\text { agríco } \\
\text { las }\end{array}$ & $\begin{array}{l}\text { Outro } \\
\text { s } \\
\text { bens } \\
\text { e } \\
\text { serviz } \\
\text { os }\end{array}$ & $\begin{array}{l}\text { Servizos de } \\
\text { intermedia } \\
\text { ción } \\
\text { financeira* }\end{array}$ & $\begin{array}{l}\text { (C) } \\
\text { Total } \\
\text { serviz } \\
\text { os }\end{array}$ & $\begin{array}{l}\text { C/A } \\
(\%)\end{array}$ & $\begin{array}{l}\text { C/ B } \\
\text { (\%) }\end{array}$ \\
\hline 1990 & $\begin{array}{l}1.470,7 \\
6\end{array}$ & 505,04 & 24,20 & 57,43 & 31,94 & 4,29 & 8,89 & : & $\begin{array}{l}126,7 \\
5\end{array}$ & $\begin{array}{l}8,6 \\
2\end{array}$ & $\begin{array}{l}25, \\
10\end{array}$ \\
\hline 1991 & $\begin{array}{l}1.601,5 \\
1\end{array}$ & 511,93 & 23,79 & 56,51 & 33,16 & 3,96 & 8,90 & : & $\begin{array}{l}126,3 \\
1\end{array}$ & $\begin{array}{l}7,8 \\
9\end{array}$ & $\begin{array}{l}24 \\
67\end{array}$ \\
\hline 1992 & $\begin{array}{l}1.436,0 \\
5\end{array}$ & 489,28 & 30,31 & 59,12 & 33,77 & 4,20 & 10,88 & : & $\begin{array}{l}138,2 \\
7\end{array}$ & $\begin{array}{l}9,6 \\
3\end{array}$ & $\begin{array}{l}28, \\
26\end{array}$ \\
\hline 1993 & $\begin{array}{l}1.478,7 \\
8\end{array}$ & 485,68 & 34,04 & 60,83 & 34,38 & 3,78 & 10,00 & $:$ & $\begin{array}{l}143,0 \\
3\end{array}$ & $\begin{array}{l}9,6 \\
7\end{array}$ & $\begin{array}{l}29, \\
45\end{array}$ \\
\hline 1994 & $\begin{array}{l}1.856,8 \\
4\end{array}$ & 512,19 & 32,77 & 75,39 & 37,75 & 3,88 & 6,23 & $:$ & $\begin{array}{l}156,0 \\
2\end{array}$ & $\begin{array}{l}8,4 \\
0\end{array}$ & $\begin{array}{l}30, \\
46\end{array}$ \\
\hline 1995 & $\begin{array}{l}2.006,2 \\
1\end{array}$ & 531,26 & 34,47 & 80,69 & 35,83 & 6,59 & 6,37 & : & $\begin{array}{l}163,9 \\
4\end{array}$ & $\begin{array}{l}8,1 \\
7\end{array}$ & $\begin{array}{l}30 \\
86\end{array}$ \\
\hline 1996 & $\begin{array}{l}1.946,0 \\
0\end{array}$ & 554,22 & 42,47 & 83,12 & 40,64 & 4,66 & 6,28 & : & $\begin{array}{l}177,1 \\
7\end{array}$ & $\begin{array}{l}9,1 \\
0\end{array}$ & $\begin{array}{l}31, \\
97\end{array}$ \\
\hline 1997 & $\begin{array}{l}1.787,4 \\
2\end{array}$ & 624,80 & 42,97 & 92,90 & 36,92 & 5,22 & 6,68 & : & $\begin{array}{l}184,6 \\
8\end{array}$ & $\begin{array}{l}10 \\
33\end{array}$ & $\begin{array}{l}29, \\
56\end{array}$ \\
\hline 1998 & $\begin{array}{l}1.852,0 \\
4\end{array}$ & 591,02 & 42,88 & 88,08 & 43,70 & 5,81 & 5,89 & : & $\begin{array}{l}186,3 \\
6\end{array}$ & $\begin{array}{l}10, \\
06\end{array}$ & $\begin{array}{l}31, \\
53\end{array}$ \\
\hline 1999 & $\begin{array}{l}1.707,6 \\
7\end{array}$ & 700,40 & 50,94 & 105,63 & 38,46 & 5,90 & 5,14 & $:$ & $\begin{array}{l}206,0 \\
7\end{array}$ & $\begin{array}{l}12, \\
07\end{array}$ & $\begin{array}{l}29, \\
42\end{array}$ \\
\hline 2000 & $\begin{array}{l}1.653,6 \\
6\end{array}$ & 788,28 & 47,55 & 88,40 & 36,37 & 9,64 & 2,44 & : & $\begin{array}{l}184,4 \\
0\end{array}$ & $\begin{array}{l}11, \\
15\end{array}$ & $\begin{array}{l}23, \\
39\end{array}$ \\
\hline $\begin{array}{l}\text { Var. } \\
90- \\
00\end{array}$ & 12,44 & 56,08 & 96,47 & 53,92 & 13,88 & 124,96 & $-72,56$ & $:$ & 45,49 & & \\
\hline $2000^{\mathrm{i}}$ & $\begin{array}{l}1.820,1 \\
4\end{array}$ & 668,7 & : & : & : & 4,37 & : & : & : & : & $:$ \\
\hline 2001 & $\begin{array}{l}1.998,2 \\
3\end{array}$ & 715,47 & 45,47 & 58,01 & 31,53 & 3,91 & 17,28 & : & $\begin{array}{l}156,2 \\
0\end{array}$ & $\begin{array}{l}7,8 \\
2\end{array}$ & $\begin{array}{l}21, \\
83\end{array}$ \\
\hline 2002 & $\begin{array}{l}2.048,2 \\
4\end{array}$ & 801,54 & 50,31 & 61,48 & 33,70 & 2,40 & 19,66 & $:$ & $\begin{array}{l}167,5 \\
5\end{array}$ & $\begin{array}{l}8,1 \\
8\end{array}$ & $\begin{array}{l}20, \\
90\end{array}$ \\
\hline 2003 & $\begin{array}{l}2.106,8 \\
6\end{array}$ & 903,81 & 60,73 & 59,5 & 33,54 & $:$ & 16,51 & $:$ & $\begin{array}{l}170,2 \\
8 \\
\end{array}$ & $\begin{array}{l}8,0 \\
8 \\
\end{array}$ & $\begin{array}{l}18, \\
84\end{array}$ \\
\hline 2004 & $\begin{array}{l}2.153,5 \\
1\end{array}$ & 937,02 & 59,81 & 59,91 & 32,06 & $:$ & 14,34 & $:$ & $\begin{array}{l}166,1 \\
2\end{array}$ & $\begin{array}{l}7,7 \\
1\end{array}$ & $\begin{array}{l}17 \\
73\end{array}$ \\
\hline 2005 & $\begin{array}{l}2.124,6 \\
5\end{array}$ & 952,25 & 53,17 & 84,93 & 34,32 & : & 8,56 & $:$ & $\begin{array}{l}180,9 \\
8\end{array}$ & $\begin{array}{l}8,5 \\
2\end{array}$ & $\begin{array}{l}19, \\
01\end{array}$ \\
\hline 2006 & $\begin{array}{l}2.382,9 \\
7\end{array}$ & 1010,94 & 52,71 & 71,32 & 34,66 & 8,61 & 15,39 & $:$ & $\begin{array}{l}182,6 \\
9\end{array}$ & $\begin{array}{l}7,6 \\
7\end{array}$ & $\begin{array}{l}18, \\
07\end{array}$ \\
\hline 2007 & $\begin{array}{l}2.680,3 \\
9\end{array}$ & 1050,39 & 52,12 & 78,64 & 26,23 & 7,33 & 42,87 & : & $\begin{array}{l}207,1 \\
9\end{array}$ & $\begin{array}{l}7,7 \\
3\end{array}$ & $\begin{array}{l}19, \\
73\end{array}$ \\
\hline 2008 & $\begin{array}{l}2.728,8 \\
0\end{array}$ & 1084,6 & 56,86 & 83,38 & 28,38 & 8,81 & 61,27 & : & $\begin{array}{l}238,7 \\
0\end{array}$ & $\begin{array}{l}8,7 \\
5 \\
\end{array}$ & $\begin{array}{l}22, \\
01\end{array}$ \\
\hline $\begin{array}{l}\text { Var. } \\
01- \\
08\end{array}$ & 36,56 & 51,59 & 25,05 & 43,73 & $-9,99$ & 125,23 & $\begin{array}{l}254,5 \\
7\end{array}$ & $:$ & 52,82 & & \\
\hline 2009 & $:$ & $:$ & $:$ & $:$ & $:$ & 8,02 & $:$ & $:$ & $:$ & $:$ & $:$ \\
\hline 2010 & $\begin{array}{l}3.063,6 \\
9\end{array}$ & 1599,44 & 58,14 & 141,74 & 29,27 & 8,27 & 22,02 & $:$ & $\begin{array}{l}259,4 \\
4\end{array}$ & $\begin{array}{l}8,4 \\
7\end{array}$ & $\begin{array}{l}16, \\
22\end{array}$ \\
\hline 2011 & $\begin{array}{l}3.078,4 \\
6\end{array}$ & 1645,78 & 60,78 & 137,91 & 31,82 & 7,70 & 18,94 & 10,47 & $\begin{array}{l}267,6 \\
1\end{array}$ & $\begin{array}{l}8,6 \\
9 \\
\end{array}$ & $\begin{array}{l}16, \\
26\end{array}$ \\
\hline 2012 & $\begin{array}{l}3.191,8 \\
0\end{array}$ & 1763,7 & 60,04 & 143,58 & 32,01 & 8,05 & 17,36 & 9,07 & $\begin{array}{l}270,1 \\
1\end{array}$ & $\begin{array}{l}8,4 \\
6\end{array}$ & $\begin{array}{l}15, \\
32\end{array}$ \\
\hline 2013 & $\begin{array}{l}3.653,6 \\
6\end{array}$ & 1958,97 & 58,45 & 151,81 & 32,41 & 7,36 & 16,08 & 9,44 & $\begin{array}{l}275,5 \\
5\end{array}$ & $\begin{array}{l}7,5 \\
4\end{array}$ & $\begin{array}{l}14, \\
07\end{array}$ \\
\hline $\begin{array}{l}\text { Var.1 } \\
0-13\end{array}$ & 19,26 & 22,48 & 0,53 & 7,10 & 10,73 & $-11,06$ & $-26,98$ & $:$ & 6,21 & & \\
\hline
\end{tabular}

* "Servizos de intermediación financeira" 2011-2013 Magrama. En anos anteriores inclúense en "Outros bens e servizos" Fonte: Elaboración propia a partir de: MAGRAMA: Evolución das macromagnitudes agrarias rexionais, 19902000, Consellería do Medio Rural e do Mar (estimacións): Contas Económicas da Agricultura 2000i-2008, Eurostat: Economic Accounts of Agriculture 2010. MAGRAMA: Contas rexionais da agricultura. Resultados 2011-2013 


\begin{tabular}{|llllll|}
\hline \multicolumn{6}{|c|}{$\begin{array}{r}\text { Táboa 4. Evolución das magnitudes PA, CI e das ratios CI/ PA e Servizos/ PA. En } \\
\text { termos reais (base 1990) }\end{array}$} \\
\hline & PA & CI & Servizos & CI/ PA (\%) & Servizos/ PA (\%) \\
\hline $\mathbf{1 9 9 0}$ & $1.470,76$ & 505,04 & 126,75 & 34,34 & 8,62 \\
\hline $\mathbf{2 0 0 0}$ & $1.342,82$ & 607,75 & 142,17 & 45,26 & 10,59 \\
\hline Variación 1990-2000 & $-8,70$ & 20,34 & 12,17 & & \\
\hline $\mathbf{2 0 0 0}$ & $1.478,00$ & 515,56 & $142,17 *$ & 34,88 & 9,62 \\
\hline $\mathbf{2 0 1 3}$ & $1.838,57$ & 615,48 & 132,17 & 33,48 & 7,19 \\
\hline Variación 2000i-2013 & 24,40 & 19,38 & $-7,03$ & & \\
\hline
\end{tabular}

2000i Dato da Consellería de Medio Rural. *Dato do Magrama. A magnitude PA está deflactada en base ao índice de prezos percibidos polos agricultores. Os CI e Servizos están deflactados en base ao índice de prezos pagados polos agricultores. Fonte: Elaboración propia a partir de: MAGRAMA: Evolución das macromagnitudes agrarias rexionais 1990-2000. Consellería do Medio Rural e do Mar (estimacións): Contas Económicas da Agricultura 2000-2008. IGE: Contas Económicas de Galicia

Afundación (2014): índices de prezos pagados e percibidos polos agricultores

Ao poñer en relación o peso dos "Servizos" sobre as magnitudes obsérvase que a importancia relativa dos servizos sobre CI oscila entre o 23\% e o 32\% ao longo da década, e que a cantidade de servizos necesarios para producir unha unidade de PA é máis estable e varía entre o 8\% e 0 $12 \%$.

A serie de datos correspondente á década de 2000 non é tan precisa como a anterior con respecto ás partidas de servizos e ofrece dúbidas sobre a súa fiabilidade. Entre 2001 e 2008 a PA e os CI aumentaron notablemente (36,6 e 51,6\%, respectivamente). Con respecto aos servizos, os importes relativos a "Mantemento de materiais", "Gastos veterinarios" e "Mantemento de edificios" son coherentes cos niveis na década anterior, as dúas primeiras partidas rexistran aumentos nestes anos. En cambio, presentan grandes oscilacións os gastos en "Servizos agrícolas" e "Outros bens e servizos"; nestes casos, detéctase unha falta de datos ou estimacións á baixa nos primeiros anos e ademais a segunda partida é moi variable, e resulta pouco transparente especialmente polos elevados importes rexistrados en 2007 e 2008.

Por último, entre 2010 e 2013 o incremento do gasto en Servizos é máis leve nos anos máis recentes, e mesmo hai una caída na partida de "Servizos Agrícolas".

Para ter unha visión máis realista da terciarización convén analizar as series de datos reais. A falta de índices axeitados para cada unha das partidas de "Servizos" desaconsella a súa deflactación. Porén, realízase unha aproximación (ver Táboa 4), que permite facer certas observacións: en xeral, obsérvase un aumento da terciarización entre 1990 e 2000, namentres que esta tende a frearse na década máis recente. A evolución parece coherente coa importancia global dos consumos intermedios en relación á PA. Porén, é necesario tomar con cautela este resultado, debido ás deficiencias dos datos relativos a "Servizos" a partir do ano 2000.

Un dos factores explicativos da terciarización das economías ten que ver coa externalización de actividades, é dicir, coa realización por axentes externos de tarefas propias do proceso producivo doutras empresas. A través dos datos recollidos na Táboa 3 ("Servizos agrícolas") constatamos como este fenómeno é evidente tamén no sector agrario galego. Galicia presenta uns trazos propios de externalización de tarefas agrarias, que se poden apreciar mellor a 
través dos datos do Censo Agrario e da Enquisa de Estruturas. O Gráfico 1 sintetiza a evolución da contratación externa nas explotacións galegas para os anos 2009 e 2013 segundo o tamaño da superficie agrícola útil das explotacións.

\section{Gráfico 1. Evolución da distribución da contratación externa, por estratos de} SAU (2009-2013)

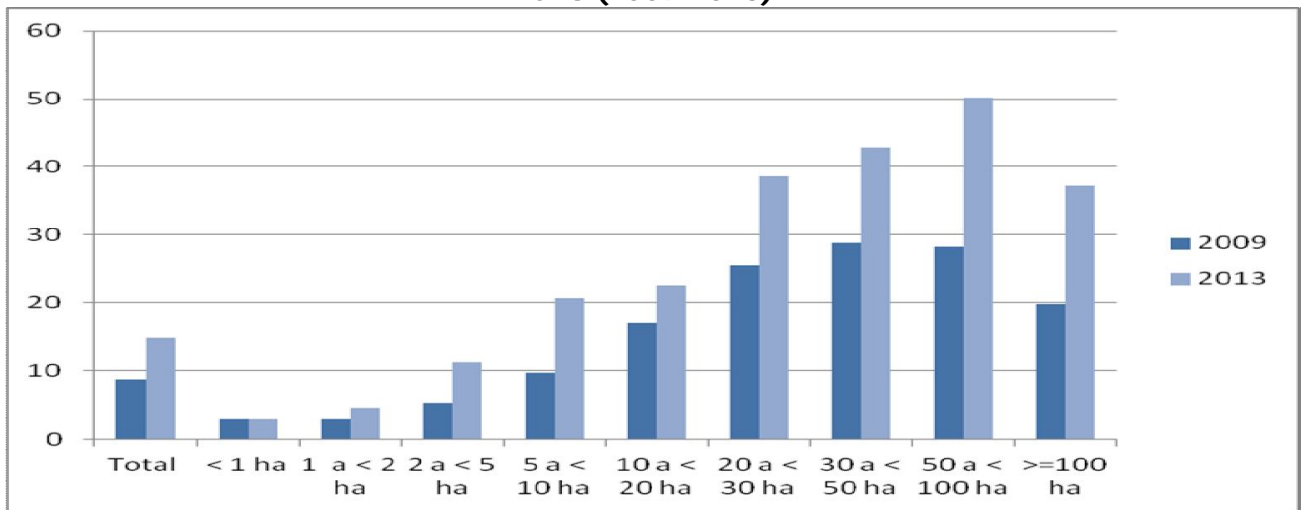

Fonte: Elaboración propia a partir de: INE (Censo Agrario 2009, Enquisa de Estruturas 2013)

En primeiro lugar, obsérvase que a externalización de tarefas é un fenómeno aparentemente relacionado co tamaño das explotacións; percébese como unha tendencia especialmente importante nos estratos de 20 a 100 hectáreas de SAU.

En segundo lugar, entre 2009 e 2013 prodúcese un aumento da externalización en xeral, e malia que é de maior magnitude nos estratos superiores, tamén destaca a maior importancia desta fórmula entre as explotacións de 2-10 hectáreas, nas que chega a máis do dobre neses anos.

A evidencia da terciarización do sector agrario galego a través dos datos estatísticos é bastante limitada e non permite entender axeitadamente o fenómeno. No seguinte apartado discutimos as tendencias observadas coa literatura existente e apuntamos dende un punto de vista máis cualitativo os principais cambios que afectaron ao sector ao longo das últimas tres décadas e que poden explicar a crecente importancia dos servizos á agricultura.

\section{Discusión}

A análise dos datos estatísticos dispoñibles permitiron evidenciar a existencia dunha tendencia á terciarización do sector agrario galego. En concreto, constatouse a importancia dos servizos máis directamente relacionados co proceso produtivo agrario, como os servizos veterinarios e os servizos agrícolas e gandeiros. Outros servizos, como as actividades de asesoramento empresarial e os servizos de análise técnica, quedan parcialmente reflectidos na partida de "Outros bens e servizos" das Contas Económicas da Agricultura.

As tendencias de terciarización do sector agrario galego observadas resultan coherentes coa hipótese mantida na literatura sobre a explicación da terciarización das economías en xeral co aumento dos servizos a empresas e sobre a crecente imbricación entre actividades de servizos e actividades doutra natureza.

En liña coa literatura sobre a terciarización da agricultura, a terciarización do sector agrario galego reflicte a importancia da externalización de tarefas. Neste senso, constatouse como a contratación de traballos a personal externo ás explotacións está relacionada coa dimensión das explotacións medida a través da superficie agraria útil. Se ben os datos dispoñibles non permiten aproximar de forma pormenorizada o fenómeno, a mesma estrutura do sector agrario galego apunta a que principalmente a orientación produtiva das explotacións (que condiciona as características, as tarefas e a complexidade tecnolóxica do proceso produtivo), é 
un factor chave na explicación das pautas de externalización e, como consecuencia, da terciarización.

A estrutura laboral das explotacións, os resultados económicos e outros factores non rexistrados a través das fontes estatísticas (por exemplo a tradición da zona, a existencia de empresas de servizos na zona) poderían axudar a explicar mellor as pautas de externalización, tal e como se puxo de relevo en certos estudos (Gallego Bono, 2010; Langreo, 2002; MoraguesFaus, 2014).

A falta datos de maior fiabilidade e en maior detalle non permite dar unha explicación máis pormenorizada das pautas de terciarización no sector agrario galego. Porén, partindo do marco teórico da economía evolucionista e en particular da perspectiva e os conceptos das teorías de Sistemas Sectoriais de Innovación (Malerba, 2002) e de Sistemas Socio-Técnicos (Geels, 2004) podemos propoñer certos factores que na súa co-evolución determinaron a transformación do sector ao longo dos últimos anos e, en definitiva, a súa terciarización ${ }^{1}$.

O cambio tecnolóxico sectorial é un deses factores. Como indicamos anteriormente, o sector agrario galego levou a cabo dende a década de 1960 un intenso proceso capitalizador do seu proceso produtivo, con investimentos notables en mecanización e automatización, novas técnicas de estabulación e sistemas para muxir, de tratamento e almacenaxe do leite, sistemas de rego automático, cambios nas especies e procesos vitivinícolas, novos inputs, tratamentos zoosanitarios e fitosanitarios (Vence, 2000). Cambios tecnolóxicos que se viron acompañados de innovacións organizativas, relativas a formas de manexo, pautas de control da calidade e hixiene dos produtos, cambios na organización e xestión máis complexa das explotacións.

Dadas as características dos agricultores, que traballaban as terras e xestionaban as súas explotacións case exclusivamente en base á súa experiencia, e a falta dunha especialización funcional interna da explotación pola práctica ausencia dun cadro de persnal, moitos deses cambios tiveron que se apoiar na contratación externa de servizos ou no acceso aos mesmos a través das cooperativas e outras fórmulas asociativas (Pereira Sánchez, 2016).

Outro factor vén dado polos cambios institucionais e de mercado. Ao longo das últimas tres décadas o sector agrario galego viuse afectado pola liberalización comercial e a competencia global determinada pola adhesión á Unión Europea. A Política Agraria Común (PAC), a través das súas sucesivas reformas, foi establecendo maiores requisitos relativos ao control dos aspectos sanitarios e de calidade dos produtos agrarios, así como aos impactos medioambientais dos procesos produtivos. A administración pública galega foi respondendo ao novo marco institucional e de mercado con sucesivas medidas de fomento da competitividade do sector, como os plans de mellora xenética gandeira, a promoción da realización de programas de xestión técnico-económica das explotacións, o establecemento de servizos oficiais de vixiancia e control de doenzas de animais, etc. (Pereira Sánchez, 2016).

As estatísticas dispoñibles que analizamos non reflicten axeitadamente a importancia dos servizos de extensión e transferencia tecnolóxica. Porén, non debemos pasar por alto a importancia destes servizos na terciarización do sector. Dende mediados dos anos 50 ata mediados dos 80, o Servizo de Extensión Agraria (SEA) cumpriu un papel fundamental na modernización e difusión de innovacións no sector agrario galego. Unha parte do SEA transformouse daquela nas Oficinas Agrarias Comarcais (OACs) con funcións de xestión administrativa, namentres que o servizo orientado á extensión e dinamización do rural foi substituído en Galicia (en cumprimiento do R 1782/ 2003/ CE sobre a obriga de establecer un sistema para aconsellar sobre a xestión de terras e explotacións) por un modelo privado de

1 A análise dos factores explicativos da terciarización do sector agrario galego está fondamente detallado na tese doctoral de Pereira Sánchez (2016). 
asesoramento, sobre a base da asociación voluntaria e a demanda dos agricultores (Pereira Sánchez, 2016).

Os cambios inducidos polas medidas políticas, ben a través de instrumentos coercitivos ou ben a través de incentivos económicos deron lugar así a asociacións de agricultores para a prestación colectiva dalgúns dos servizos. Noutros casos, foron outras estructuras xa existentes, enfocadas en prestar servizos ao sector, as que foron asumindo máis funcións e ampliando a súa carteira de servizos aos agricultores, como as cooperativas agrarias e as organizacións profesionais agrarias (Pereira Sánchez, 2016).

\section{Conclusións}

Neste artigo estudamos a terciarización do sector agrario galego como unha innovación de sistema, que vén dada por cambios de carácter incremental acontecidos na co-evolución dinámica das estruturas agrarias, os cambios tecnolóxicos, institucionais e de mercado.

En concreto, a terciarización do sector agrario caracterízase pola importancia dos servizos máis directamente relacionados co proceso produtivo (servizos veterinarios e servizos agrícolas), así como por servizos intensivos en coñecemento, como os de tipo administrativo e de asesoramento empresarial. A demanda destes servizos por parte das explotacións agrarias constitúe un proceso de adaptación suave do sector á crecente complexidade da actividade agraria, dados os numerosos requisitos á produción de alimentos.

A significación do presente estudo ten que ver co recoñecemento da contribución dos servizos e da existencia de vencellos entre estes e as actividades tradicionais, á competitividade da economía. Neste senso, é importante analizar a natureza e contido dos servizos á agricultura, e tratar de discernir en que medida estes poden contribuír á verdadeira dinamización do sector ou soamente apoiar o cumprimiento de obxectivos de carácter político-instrumental. O estudo é ademais relevante por canto apunta cara a diversificación de actividades no medio rural, como unha ferramenta chave para manter o emprego, a competitividade e a cohesión dentro do territorio rexional.

O traballo realizado pon de manifesto as notables deficiencias da información estatística relativa ao sector en Galicia. Neste senso, convén mellorar a recollida de información na elaboración de Miogal para dar conta da importancia dos servizos á agricultura.

A contribución deste artigo é sen dúbida un primeiro paso que revela a terciarización como unha dimensión da innovación do sector agrario. Porén, as limitacións encontradas nos datos estatísticos apuntan á necesidade de investigacións máis detalladas, baseadas en estudos de caso e información cualitativa. Neste senso, o tema traballouse máis amplamente na tese doutoral da co-autora e tería continuidade no futuro, a través da ampliación das liñas de investigación, como o estudo sobre 0 impacto dos servizos na competitividade e sustentabilidade do sector agrario galego.

\section{BIBLIOGRAFÍA}

Afundación. (2016): A Economía Galega. Informe 2015. Retrieved from http:// www.afundacion.org/ es/ publicacion/ a economia_galega._informe 2015

Aparicio, S. T., Berenguer, P., \& Rau, V. (2004): "Modalidades de intermediación en los mercados de trabajo rurales en Argentina". Cuadernos de Desarrollo Rural, (53), pp. 59-79.

Arnalte, E. (1989): "Estructura de las explotaciones agrarias y externalización del proceso productivo. Implicaciones para el debate sobre el proteccionismo". ICE, 666, pp. 101-117.

Arnalte, E. (2002): "Ajuste estructural y cambios en los modelos productivos de la agricultura española". In J. J. González Rodríguez \& C. Gómez Benito (Eds.), Agricultura y sociedad en el cambio de siglo (pp. 391-426). Madrid: McGraw-Hill Interamericana de España.

Balmann, A., Dautzenberg, K., Happe, K., \& Kellermann, K. (2006): "On the dynamics of structural change in agriculture: Internal frictions, policy threats and vertical integration". Outlook on Agriculture, 35(2), pp. 115-121. http:/ / doi.org/ 10.5367/ 000000006777641543 
Boden, M., \& Miles, I. (2000): Services and the Knowledge-based Economy. (M. Boden \& I. Miles, Eds.). book, London: Continuum.

Bourgeois, L. (1987): "L’agriculture et les services: divorce ou symbiose?" Économie Rurale, 177(1), pp. 10-17. http:/ / doi.org/ 10.3406/ ecoru.1987.3795

Compés López, R., López Iglesias, E., \& Martínez Gómez, V. (2011): "Evolución de la PAC y evaluación de las propuestas legislativas para la Reforma de 2013". In J. M. García Álvarez-Coque \& F. Sineiro García (Eds.), Apoyo público a la agricultura española 2003-2010 (pp. 25-70). Ministerio de Agricultura, Pesca y Alimentación.

Cuadrado Roura, J. R., \& Del Río Gómez, C. (1987): Cambio estructural y evolución de los servicios en el área de la OCDE (1960-1984) (No.03/1987).

Cuadrado Roura, J. R., \& Del Río Gómez, C. (1993): Los servicios en España. Madrid: Ediciones Pirámide.

Díaz Díaz, C. (1979): "A agricultura e o capitalismo en Galicia. O proceso de modernización da agricultura galega". Revista Galega de Estudios Agrarios, 1(Xaneiro-Xuño).

Errington, A. (1998): "The increasing flexibility of machinery and labour inputs to UK farming". Etud. Rech. Syst. Agraires Dév., 31, pp. 371-385.

Eurostat. (2000): Manual on the economic accounts for Agriculture and Forestry EAA/ EAF 97 (Rev.1.1).Luxembourg: Office for Official Publications of the European Communities.

Fernández Leiceaga, F., \& López Iglesias, E. (2000): Estrutura Económica de Galiza. Santiago de Compostela: Laiovento.

Gallego Bono, J. R. (2010): "La agricultura a tiempo parcial y la externalización de servicios agrarios como vehículo del cambio estructural". Revista Española de Estudios Agrosociales y Pesqueros, 225, pp. 13-45.

Geels, F. W. (2004): "From sectoral systems of innovation to socio-technical systems". Research Policy, 33(6-7), 897-920. http:/ / doi.org/ 10.1016/ j.respol.2004.01.015

Goodman, D., Sorj, B., \& Wilkinson, J. (1987): From farming to biotechnology. A theory of agroindustrial development. Oxford; New York: Basil Blackwell.

Harff, Y., \& Lamarche, H. (1998): "Le travail en agriculture: nouvelles demandes, nouveaux enjeux". Économie Rurale, 244(1), pp.3-11. http:/ / doi.org/ 10.3406/ ecoru.1998.4995

Igata, M., Hendriksen, A., \& Heijman, W. (1997): "Agricultural outsourcing: A comparison between the Netherlands and Japan". Applied Studies in Agribusiness and Commerce - APSTRACT.

Labarthe, P. (2009): "Extension services and multifunctional agriculture. Lessons learnt from the French and Dutch contexts and approaches". Journal of Environmental Management, 90 Suppl 2, pp. 193-202. http:/ / doi.org/ 10.1016/j.jenvman.2008.11.021

Langreo, A. (2002): "La externalización del trabajo agrario y las empresas de servicios a la agricultura". Economía Agraria y Recursos Naturales, 2, pp. 45-67.

López-Iglesias, E. (1996): Movilidad de la tierra y dinámica de las estructuras agrarias en Galicia. Madrid: Ministerio de Agricultura, Pesca y Alimentación.

López-Iglesias, E., Sineiro-García, F., \& Lorenzana-Fernández, R. (2013): "Processes of farmland abandonment: land use change and structural adjustment in Galicia (Spain)". In D. Ortiz-Miranda, A. Moragues-Faus, \& E. Arnalte-Alegre (Eds.), Agriculture in Mediterranean Europe: Between Old and New Paradigms (Vol. 19, pp. 91-120). CHAP, Emerald Group Publishing Limited. http:/ / doi.org/ doi:10.1108/ S1057-1922(2013)0000019007

Malerba, F. (2002): "Sectoral systems of innovation and production". Research Policy, 31(2), pp. 247-264. http:// doi.org/ 10.1016/ S0048-7333(01)00139-1

Melero, A., \& Calatrava, A. (2007): "Procesos de terciarización en el medio rural". In J. Sanz Cañada (Ed.), El futuro del mundo rural (pp. 73-101). Síntesis.

Miles, I. (1993): "Services in the new industrial economy". Futures, 25(6), pp. 653-672. http:/ / doi.org/ 10.1016/ 0016-3287(93)90106-4

Moragues-Faus, A. (2014): "How is agriculture reproduced? Unfolding farmers' interdependencies in small-scale Mediterranean olive oil production". Journal of Rural Studies, 34, pp. 139-151. http:/ / doi.org/ 10.1016/j.jrurstud.2014.01.009 
Pereira Sánchez, Á. (2016): Terciarización e servizalización na innovación do sector agrario. Factores impulsores e efectos na sustentabilidade da gandería e da viticultura en Galicia. University of Santiago de Compostela. [Tesis doctoral].

Prager, K., Labarthe, P., Caggiano, M., \& Lorenzo-Arribas, A. (2016) : "How does commercialisation impact on the provision of farm advisory services? Evidence from Belgium, Italy, Ireland and the UK". Land Use Policy, 52(JANUARY), pp. 329-344. http:/ / doi.org/ 10.1016/j.landusepol.2015.12.024 Pugliese, E., \& Ceriani-Sebregondi, F. (1981): "Destrutturazione aziendale, familia e classi sociali in Agricoltura". Agricoltura E Societá, 4.

Rubalcaba Bermejo, L., \& Kox, H. (2009): "El crecimiento de los servicios a empresas en Europa". In L. Rubalcaba Bermejo \& H. Kox (Eds.), Los servicios a empresas en el crecimiento económico europeo (pp. 41-70). Madrid: Marcial Pons.

\section{Anexo}

Táboa A.1. Consumos intermedios de servizos nas Contas Económicas da Agricultura

\begin{tabular}{ll}
\hline Bens e servizos & Contidos \\
\hline Gastos veterinarios & Medicinas \\
& Honorarios de veterinarios \\
\hline Mantemento de & Compras de bens e servizos de mantemento \\
materiais & Reparacións dos bens de capital \\
\hline \multirow{3}{*}{ Mantemento de } & Compras de materiais, \\
edificios & Custos laboriais e \\
& Custos xerais para o mantemento de edificios agrarios ou outras \\
& estruturas \\
\hline Servizos agrícolas & Contratación de maquinaria e equipo co correspondente traballo \\
\hline & Rendas de alugueiro de edificios e outros activos de capital \\
& Revisións médicas dos empregados \\
& Honorarios de consultores agrarios, contadores, fiscais, xurídicos, etc. \\
& Servizos de investigación científica, de investigación de mercado e \\
& publicidade, formación de empregados \\
& Servizos de transporte \\
& Custos de telecomunicacións e postais \\
& Remuneración de servizos contidos nas primas brutas de seguros \\
& agrarios \\
& Servizos de sementais \\
& Cargas bancarias (non intereses) \\
& Cotas de pertenza a asociacións profesionais \\
& Subscricións a cooperativas agrarias \\
& Custos de control leiteiro e rexistro xenealóxico \\
& Gasto en inseminación artificial e castración \\
& Pagos polo uso de activos intanxibles \\
Taxas públicas por licenzas ou permisos para a realización de actividades \\
comerciais ou profesionais \\
Pequenas ferramentas, roupa de traballo, equipo duradeiro de baixo \\
valor
\end{tabular}

Fonte: Elaboración propia a partir de Eurostat (2000) 